\title{
A Tutor-Led Collaborative Modelling Approach to Teaching Paraphrasing to International Graduate Students
}

\author{
Antoanela Denchuk \\ University of Manitoba
}

\begin{abstract}
Language learners are at particular risk of being accused of plagiarism, and this is often due to incorrect paraphrasing and quoting practices. Tertiary institutions tend to provide rudimentary citation resources through their academic integrity initiatives. Handouts, webinars and one-hour workshops may be enough for undergraduate writers who receive more elaborate instruction and practice opportunities in their classes, but for international graduate students with little to no instruction on source use in their undergraduate degrees, these resources are not enough. These writers often need more conceptual and procedural clarity to paraphrase and use sourced information correctly in their writing. This article introduces a student-centred, collaborative modelling approach and a 5-step procedure for teaching paraphrasing to multilingual graduate students in one-to-one writing center tutoring sessions.
\end{abstract}

Keywords: Paraphrasing; Academic Writing; International Graduate Students; Writing Centres; Multilingual 
Volume 30, 2020

http://journals.sfu.ca/cjsdw

\section{Introduction}

Post-secondary international students with English as an additional language are at particular risk of being accused of plagiarism. This is often due to incorrect paraphrasing and citation practices, which may lead to inadvertent plagiarism (Bradshaw \& Baluja, 2011; Soto, Anand \& McGee, 2004). Post-secondary institutions have taken various steps to reduce plagiarism by providing educational resources through their academic integrity initiatives. These resources are often in the form of handouts or webpages that provide guidelines for source use and examples of correct and incorrect paraphrasing and general academic integrity workshops or webinars that cover a range of academic integrity issues from plagiarism to inappropriate collaboration to personation. These resources are rarely adapted to suit the needs of students for whom English is an additional language and tend to offer very few opportunities for meaningful application of concepts and practice of processes. Students receive very little feedback and correction on their source use or language use, so they may know what paraphrasing is and that they need to acknowledge sources. Still, when asked to write a paraphrase and correctly embed it in a paragraph, they are unable to do so correctly because they have not applied this knowledge in a meaningful way. Without proper correction and feedback, students end up getting feedback only when they fail to use sources correctly in a course. By that point, the correction comes with a loss of grades or a plagiarism allegation.

Like all developing writers, multilingual writers need to have a clear understanding of fundamental writing elements such as paraphrases, quotations, in-text and reference citations, and they should be able to incorporate these into their writing appropriately. Post-secondary institutions cannot assume that non-native second language writers are going to understand foreign writing concepts and be able to use these as easily as native speakers of English; native English speakers may have learned the difference between a paraphrase and a quotation in grade school, as is often the case with Canadian-born native speakers of English. Furthermore, writers need to know and use the procedures involved in producing these rhetorical functions correctly, and this often requires real-time feedback and explicit steps that students may need to follow before they can produce a free paraphrase or a correctly embedded quotation. Handouts, one-hour long workshops and online webinars designed for all students merely skim the teaching of these culturally embedded conventions of Western source-based writing practices (Pennycook, 1996). Teaching Western academic conventions about textual borrowing requires a strategy that involves both conceptual clarity and procedural scaffold- 
Volume 30, 2020

http://journals.sfu.ca/cjsdw

ing and is sensitive to the graduate multilingual learners' developing language and cultural understanding.

Given the diverse cultural, linguistic and proficiency levels of multilingual graduate students, individualized resources may be the most sustainable way to fill in individual gaps in knowledge about Western citation practices. Most university writing centres have as their primary objective the support of student academic writing development. As such, they are opportune spaces for teaching citation practices and source integration in a more effective way. One-to-one individualized tutoring sessions fit the needs of multilingual writers well because they can offer a flexible learning time-frame, individualized diagnostic and formative assessments and student-centred direct instruction and feedback. The writing centre tutoring session can be the low-stakes environment where students can expose their academic literacy and linguistic vulnerabilities (Thomas, 2018). Furthermore, they can obtain the knowledge and support necessary to clarify misconceptions about textual borrowing, grow their English writing proficiency, and develop their writing craft and identity as second language writers. In this paper, I introduce a scaffolded, language-sensitive approach to teaching paraphrasing in the one-to-one tutoring session. This approach supports multilingual graduate students' mastery of both the conceptual and procedural aspects of paraphrasing.

\section{Theoretical and Pedagogical Orientations}

The complexity of writing practices embedded in the Western cultural context makes being an international student in a North American university particularly difficult. As Chandrasoma et al. (2004) explain, textual borrowing is "centrally concerned with questions of language, identity, education, and knowledge" (p. 172). Students' critical thinking about the practice and even a possible resistance to acculturation into Western academic writing practices may interfere with the full adoption of citation conventions that may seem foreign and contrary to what students have learned in their own countries (Peirce, 1995; Norton, 2000, 1997; Pennycook, 1996; Cananagarajah,1997; Abasi \& Graves, 2008). Furthermore, when it comes to paraphrasing sources, the mere fact that complex academic text needs to be:

- understood in a foreign language,

- processed for meaning and critically reviewed, and

- re-written in an appropriate academic register that meets grammatical and style conventions, 
makes this process much more difficult for multilingual writers as compared to native writers.

From a sociocultural theoretical perspective, teaching students for whom English is an additional language requires considering the complexity of language and academic discourse and the learners' individual needs and cultural differences. These factors are seen as affecting the conceptualization of elements of academic writing (Pennycook, 1996; Cumming, 2006; Silva, 1997; Coffin et al., 2003), in this case, source use, paraphrasing, and citing. Therefore, the teaching of academic writing and its conventions requires a flexible pedagogical approach that situates multilingual learners at the center of the learning process, allowing them to be agents in their own linguistic and authorial development. Within the English for Academic Purposes (EAP) a branch of English as an Additional Language (EAL) education, educators have incorporated pedagogical approaches that utilize direct, yet, scaffolded instruction, text and genre analysis, practice and feedback, and modelling of linguistic and rhetorical processes (Cumming, 1995; Wette, 2014, 2015). These approaches offer the multilingual learner the explicit and direct instruction on content and process needed to accomplish a writing task. These instructional supports facilitate English language proficiency, build academic literacy, and help students develop their second language writing ability.

Wette $(2014,2015)$ has explored a pedagogical approach that incorporates these elements. Wette identified teacher-led collaborative modelling as one way to expose the intricacies of the writing process, provide direct and scaffolded instruction, and reduce cognitive load. In teacher-led collaborative instruction, instructors teach textual elements explicitly, show the steps involved in the writing process by modelling the process, and provide insight into their own cognitive processing through thinkaloud protocols (Wette, 2014). In addition, instructors elicit contributions from learners and, through feedback and response to the students' revisions, eventually lead them towards producing their own texts. Essentially, the instructor moves the process forward, but the students provide the input. In one study of teachers' practices, EAP instructors who used collaborative modelling in their classes found that the students understood the expectations of the tasks and felt more confident in their own ability to produce text. The instructors appreciated this approach because they could provide direct and immediate feedback to their students as they were learning about their students' needs as writers (Wette, 2014). In this same study, Wette found that while the students appreciated the collaborative modelling process, they reported that they preferred writing on their own before engaging in collaborative writing groups. This suggests that some writers may appreciate the instructional input 
Volume 30, 2020

http://journals.sfu.ca/cjsdw

and supports but prefer making their own linguistic choices as they produce their own texts independent of the group. In the one-to-one tutoring session, writers can work independently, yet still receive feedback or collaborate with the tutor and are not bound by the constraints of group work.

Teacher-led collaborative modelling provides a promising alternative to the non-directive teaching commonly employed in tutoring sessions with multilingual writers. Teacher-led collaborative modelling aligns with recent writing centre pedagogy, which recommends explicit, direct instruction for multilingual learners and multilingual learners' preferences for explicit feedback and direct instruction (Rafoth, 2015, Harris \& Silva, 1993). In the one-to-one session, tutors can individualize instruction to meet the learners' unique language and content needs. The tutor can provide direct and explicit instruction on the characteristics of particular textual elements such as paraphrasing or quoting, model the steps in the writing process and provide feedback and support for correct language use as writers create their own text.

What follows is a description of an application of teacher-led collaborative modelling to the teaching of paraphrasing in the one-to-one tutoring session. Here, the tutor models the paraphrasing process, teaches the components and concepts behind the process explicitly, and provides feedback and correction as the students develop their own paraphrases and internalize the steps to processing the text properly.

\section{The Academic Integrity Sessions for Graduate Students}

The pedagogical intervention described in this paper emerged from my experience working with multilingual graduate international students who had been referred to me, the Academic Learning Centre's EAL specialist instructor, by the Academic Integrity Coordinator following a plagiarism decision reached by the Faculty of Graduate Studies at our large comprehensive Midwestern Canadian university. These students, who had a variety of native language backgrounds and were studying in various graduate programs, had been deemed to have plagiarized because they had not cited at all or cited incorrectly, failed to paraphrase or signal quoted text, patch paraphrased, or did not know how to follow standard citation conventions. In some cases, the plagiarism occurred despite the completion of an online academic integrity workshop, and, in some cases, despite undergoing the disciplinary process once before. 
Volume 30, 2020

http://journals.sfu.ca/cjsdw

Meeting with a writing tutor to learn the university's standard citation and source use conventions, i.e. citation, quotation, and paraphrase, is a standard, mandatory post-discipline condition at this institution, and many of the students who underwent the disciplinary process for plagiarism were required to meet with a writing tutor for one or two sessions of source use tutoring. However, in the case of the multilingual graduate students, the EAL specialist instructor identified a need for a more systematic, hands-on approach that involved a needs assessment, explicit instruction over a period of several sessions and formative assessments for learning. This led to the development of a module on textual borrowing terms and concepts, and a module focused on the paraphrasing process, which take approximately 6 hours to complete. In addition to these one-to-one sessions, students are expected to complete one paraphrasing activity at home, an in-session independent paraphrase, and a 250-word reflection, which can be completed after the sessions. If students continue to need supports beyond the six sessions, they are encouraged to continue meeting with the tutor but are not required to do so. The tutor reports that the student has completed the educational component of their post-discipline condition but does not provide any summative reports to the disciplinary committee. The following is a brief description of the academic integrity sessions, followed by a more focused discussion of the paraphrasing process sessions.

\section{The Sessions}

In the needs assessment or diagnostic session, the tutor assesses the students' writing to understand how they use sources and identify the students' particular knowledge gaps or misconceptions related to using sources. Following this assessment, students complete either both modules (terms and paraphrasing) or just the paraphrasing module. If the tutor determines that the student can correctly use in-text citations and create an appropriate reference list, the sessions begin at the paraphrasing module. However, if the students' writing shows a lack or misuse of in-text citations or references, the workshop begins with the terms module. This module introduces students to basic concepts such as in-text citations, reference list citations, paraphrasing, quoting, and summarizing, to name a few.

Students who need to start with the terms module begin by reading a short guide to using sources outside of the session. In the following session, they take a short, multiple-choice quiz that evaluates their understanding of the terms and concepts discussed in the guide. The guide, about 20 pages long, introduces basic citation styles, the various ways to incorporate sources (summary, paraphrase, and quotation), as well as citation forms (in-text and reference citation), and common style formats (APA, 
Volume 30, 2020

http://journals.sfu.ca/cjsdw

MLA, Chicago, etc.,) in simple, accessible language. The quiz assesses the students' ability to distinguish between a paraphrase and a quotation, cite in various styles, and recognize the criteria for writing a good paraphrase (i.e., changing vocabulary, grammar and order of ideas, including an in-text citation and not distorting meaning) and the difference between a paraphrase and quote. The terms "module" and "short quiz" provide the metalanguage needed to talk about the process of using sources in later sessions. However, the discussion ensuing after the quiz is perhaps most valuable because it offers an opportunity to correct misunderstandings, fill in knowledge gaps, and answer any questions students might have about foundational, source-use concepts and procedures.

Building on the students' understanding of the basic terms and concepts from the first module, the second module, paraphrasing, takes students through the paraphrasing process and begins with a review of the criteria for a good paraphrase and an activity in which the student chooses the best paraphrase from among several poor paraphrases. This module is followed by a discussion about why the student chose that particular paraphrase and a review of the basic criteria for a good paraphrase. This discussion provides another opportunity to dispel any myths about paraphrasing, reinforce the characteristics of a good paraphrase, and ensure that the concept is clear in the students' minds.

To teach the process of paraphrasing, a blackline master titled "The Five Steps to a Free Paraphrase" scaffolds the process by dividing it into five steps. The tutor and student complete these steps precisely, with the goal of offering the student a systematic model and experience of the paraphrasing process. Various teaching opportunities, such as the use of dictionaries and thesauri to understand academic vocabulary, use of brevity and academic register, clarification of grammatical rules and lexis, often emerge at various stages in the procedure. The workshop is an opportunity to address not only paraphrasing and citation practices, but also close-reading strategies needed for complex sentence structure, vocabulary and grammar in academic text, paragraphing and the function of sources in the paragraph, and various other language and writing-related tools and considerations. However, the main objective of this module is to give students an opportunity to experience the process of writing and embedding a correct paraphrase using their own linguistic resources. What follows is a description of each of the five steps in the paraphrasing process and the pedagogical actions involved in each step. 
Volume 30, 2020

http://journals.sfu.ca/cjsdw

\section{The Five-Step Process}

To prepare for the first step in the blackline master, the tutor prepares a short piece of text (two to three full sentences) from a journal article within the student's subject area or an article that the student has already read. The tutor enters the text in the first box of the blackline master, along with the link to the journal article. Students may use this link to refer to the whole article or create a full reference citation later in the process if needed. Figure 1 shows the original excerpt from Aday and Yener (2014), an article with which the student was familiar.

\footnotetext{
The objectives of this research were to determine the factors that can possibly affect consumer behaviour at the point of sale. The results of this study showed that socio-demographic properties of consumers price, product quality, package type, package attributes labels and brands had higher influence on the purchasing decision of food products. In general, therefore, it seems that consumers in Turkey were not different from other countries' consumers with respect to purchasing behaviour. It can be concluded that expectations of consumers are becoming more similar in the global world.

https://onlinelibrary-wiley-com.uml.idm.oclc.org/doi/full/10.1111/ijcs.12105
}

Figure 1. Original Text. Highlighted text will be paraphrased.

Step 1: Noticing words. The first step in the modelling process is modelling close reading. The tutor and student begin by noticing any new or difficult vocabulary and look up their definitions in a dictionary. Here there is an opportunity to talk about advanced, monolingual learners' dictionaries, and lexical concepts such as word sense, context or connotation. Jargon, technical language and proper nouns, differences between academic language and basic language for communication, and strategies for changing the vocabulary to suit the audience often arise at this step. The primary purpose of this section is to get the student past unknown vocabulary to noticing ideas and eventually to a fluent reading of the text. Figure 2 provides an example of this step of the blackline master.

Step 1: Check the words and concepts you do not understand in a monolingual dictionary. Underline any technical words and proper nouns that you will need to keep.

socio-demographic properties - characteristics of a group of people, ex. Gender, sex, age, marital status

attributes --

Figure 2: Noticing Words

Step 2: Noticing ideas. Since the cornerstone of paraphrasing is understanding the source text, close reading is essential. When paraphrasing, writers focus on ideas that appear in sentences, not 
necessarily in paragraphs, and so sentence-level considerations become important. For language learners, research suggests that fluency, and in particular, awareness of phrase boundaries and thought-chunks are closely related to comprehension (Jiang, 2016; Frazier, Carlson \& Clifton, 2006). Given this connection between phrase boundaries and comprehension, teaching students to slow down and pay attention to thought chunks promotes better comprehension of text (Rasinsky, 2011). Furthermore, when reading complex academic text, paying attention to heavily modified phrases, reduced clauses, subordination and coordination and other features of academic texts (Wong Fillmore \& Fillmore, 2012) allows readers to "unpack" the sentences and arrive at a more complete understanding of the text (Rasinsky, 2011; Wong Fillmore, n.d.). Having a designated space and time for paying close attention to the intricacies of the text reinforces the importance of slow, careful reading when text is challenging but rhetorically essential, as is the case with paraphrasing sources in order to support or develop arguments.

Procedurally, the tutors model their own deconstruction of the sentence using a think-aloud strategy. The think-aloud strategy makes the meaning-making process visible and demonstrates the type of close reading students need to engage in when paraphrasing complex academic text. Figure 3 shows how a sentence can be chunked into smaller units of meaning for close reading.

Step 2: Read the text until you are sure you understand it. Break up the original into chunks of meaning and number these chunks.

The results of this study showed (1) that socio-demographic properties of consumers $(2 \mathrm{a})$, price $(2 \mathrm{~b})$, product quality $(2 \mathrm{c})$, package type $(2 \mathrm{~d})$, package attributes $(2 \mathrm{e})$ labels and brands (2f) had higher (4) influence (3) on the purchasing decision (5) of food products (6)

Figure 3: Chunking for close reading.

Step 3. Drafting. The next step is to transcribe the meaning of the original. At this point, I let the student know that I will write my own paraphrase, but that I also want them to write their own so that we can compare the versions. They read the text once more, and when they feel confident that they understood the ideas in the sentence, they look away and write from memory, with the option to glance back at the original if needed for comprehension. I ask them to write from memory to encourage them to use their understanding of the ideas and to distance themselves from the wording of the original. This is the students' first step away from the original wording and their first attempt 
at paraphrasing. On some occasions, some students have tried to memorize the text instead of grasping the ideas, so expecting them to write without looking at the language compels them to understand the ideas in the text and think of other ways to express these ideas. When they try to paraphrase at this point, students often notice how much they initially comprehended, which gives them an objective view of the effectiveness of their own reading process and propels them to adjust their reading strategy.

I usually ask students to type their answers in a Word version of the blackline master so that we can easily compare it to the original text later, and I write my paraphrase on a piece of paper. My paraphrase will not be the focus of the later comparison, but it provides an example of how the text could be paraphrased. Figure 4 shows an example of a student's draft paraphrase.

Step 3: Cover the original, and write what you remember. Pretend that you are telling your friend what you read.

This paper got the conclusion that the consumers' choice of whether or not purchasing a type of food will be strongly affected by the price of the product, the quality of the food, what types of the food package, what the package of the food looks like, and the characteristics of the consumer such as gender, age, sex, and so on.

Figure 4. Student's Draft Paraphrase

Step 4. Comparison and revision. After the student writes the paraphrase, I copy and paste the original and the draft texts in the blackline master. When we compare the original with the draft paraphrase, we often notice that the paraphrase has remained close to the original. This gives us an opportunity to review the principles of a correct paraphrase. I might also show the student my own paraphrase so they can see that I also kept some elements from the original on my first attempt at paraphrasing, and we talk about how I might change some of my vocabulary and sentence structure choices to process the text more substantially. We also discuss whether they have omitted important chunks of information or distorted the original's meaning in any way.

At this step, as we compare the original and the draft, we create a revised paraphrase. We incorporate the insight gained from the comparison and use grammar and sentence restructuring strate- 
Volume 30, 2020

http://journals.sfu.ca/cjsdw

gies to further process the text if needed. This step involves a lot of grammar and vocabulary discussion, but by the end, we usually have a correct paraphrase. Figure 5 shows an example of this step.

Step 4. Copy and paste your paraphrase from step 3 in the box below. Perform a meaning and structure check.

Mcaning check: Check your understanding of the text against the original. Make sure you have included all the main ideas and have not changed the meaning or added extra information. Structure and word check: Make sure you have changed the language, sentence structure and idea arrangement significantly.

\begin{tabular}{|l|l|}
\hline- Changed the sentence structure & - Changed the word order \\
- Changed parts of speech & - Used a different way of defining \\
- Used synonyms & - Used different types of connecting \\
- Changed numbers to different forms & - Words \\
& - Kept key terms and proper nouns. \\
\end{tabular}

\begin{tabular}{|l|l|l|}
\hline Original & Draft paraphrase & $\begin{array}{l}\text { Revised Paraphrase } \\
\text { (corrected version of the } \\
\text { draft }\end{array}$ \\
\hline $\begin{array}{l}\text { The results of this study } \\
\text { showed (1) that socio- } \\
\text { demographic properties of } \\
\text { consumers (2a), price (2b), } \\
\text { product quality (2c), package } \\
\text { type (2d), package attributes } \\
\begin{array}{l}\text { (2e) labels and brands (2f) had } \\
\text { higher (4) influence (3) on the } \\
\text { purchasing decision (5) of } \\
\text { food products (6). }\end{array}\end{array}$ & $\begin{array}{l}\text { This paper got the conclusion } \\
\text { that the consumers' choice of } \\
\text { whether or not purchasing a } \\
\text { type of food will be strongly } \\
\text { affected by the price of the } \\
\text { product, the quality of the } \\
\text { food, what types of the food } \\
\text { package, what the package of } \\
\text { the food looks like, and the } \\
\text { characteristics of the } \\
\text { consumer such as gender, age, } \\
\text { sex, and so on. }\end{array}$ & $\begin{array}{l}\text { This paper concluded that } \\
\text { the consumers choice of } \\
\text { ahether or not to purchase } \\
\text { affected more by their own } \\
\text { social determinants, by } \\
\text { how expensive, popular or } \\
\text { superior an item is, and the } \\
\text { features of its packaging. }\end{array}$ \\
\hline
\end{tabular}

Figure 5. Comparison. Meaning and Structure Checks.

Step 5: Embedding. The next step is contextualizing the paraphrase. Here, we discuss the separation of the writer's voice and the sourced information (Graff \& Birkenstein, 2014), and discuss intext citations and the use of author-reporting words. We also talk about choosing only those parts of the original text that suit the thrust of the paragraph. Understanding paragraph structure and the functions of the components of a complete paragraph helps the student see how the paraphrase can 
Volume 30, 2020

http://journals.sfu.ca/cjsdw

support the topic sentence and the overall argument. This also helps students see the paraphrase as not only a way to translate text, but also as a way to support one's argument and connect that argument to the existing scholarly discussions on a particular topic (Hirvela \& Du, 2013). I have found that most students find this step difficult to conceptualize, but this is when we can talk about choosing only what is necessary to develop the argument and showing readers how the sourced information supports the overall argument.

To demonstrate the embedding step, I prepare a topic sentence related to the paraphrase's content in some way. If students have a good grasp of paragraphing, I encourage them to write the supporting sentences themselves and complete the paragraph independently. If they need more clarification, I use the think-aloud strategy to show my own in-text citation choices, idea parsing and the creation of the supporting sentences connecting the paraphrase to the topic sentence. Figure 6 provides an example of a student's revised paraphrase as it is embedded in the paragraph.

Step 5: Embed the revised paraphrase in your paragraph. Show how it connects to the main ideas and topic sentence. Add the appropriate transition words and any author reporting words if necessary. Make sure the paraphrase fits in the paragraph logically and your paragraph is grammatically correct. Add the in-text citation.

Marketing an expensive food product to middle class consumers can be a challenge. There are many factors that can affect middle class consumers' choices however, some factors have more influence on their decision. Smith (2002) concluded that consumers' choice of whether or not to purchase a type of food will be affected more by how expensive, popular or superior an item is. As a marketer, we need to consider all of these factors when creating a good marketing strategy to persuade the middle class consumers to buy an expensive product.

Figure 6. Embedding.

\section{Practice and Assessment}

Once the student and I have worked through the five steps and applied them, the next step in the learning process involves independent practice. I prepare another word document with a blackline master that contains a piece of text that I want them to paraphrase and a link to the full article. The student completes this at home and sends it to me for feedback. This is the student's opportunity to take as much time as they need and use their own resources to create a paraphrase independently. In the next session, I provide feedback, highlight their positive writing choices, and discuss any changes that would improve the paraphrase. We also tweak the grammar, word use, and clarity if needed. This is a great opportunity to provide feedback and instruction on vocabulary and grammar 
Volume 30, 2020

http://journals.sfu.ca/cjsdw

in a familiar context.

\section{Evaluation and Reflection}

To complete the paraphrasing module, students write a final paraphrase in the last session. This gives the tutor a sense of whether students can independently write a paraphrase and whether they will need further supports. As a final assignment, students write a short reflection paragraph to synthesize the content they have learned and further embed their developing source use practice into their academic writing schema. The reflection helps students see how they have grown as academic writers and helps them consider how they can move forward in a better way.

None of the 17 students who completed this program had negative comments about the workshop. In their sessions, most expressed gratitude for having access to this service. Their remarks suggested that they appreciated being introduced to a step-by-step process and having an opportunity to clarify their understanding of source use. Here are a few representative remarks from three students' reflections:

“The other assumption which I was ignoring previously was to ignore the new words that I don't did not know their meanings." (G)

"I knew what the academic integrity and plagiarism are. ... However, I was not clear how much the language changes we should make without plagiarism." (H)

"My assumption about paraphrase was that my paraphrases must be more concise or shorter than the original text. This assumption drove me being frustrated. After this tutoring session I understand that I need to write the original ideas in my own words no matter my paraphrase sentences are longer or shorter; even I could use several sentences and omit some unimportant ideas. Now I feel more easily to write my ideas out on the paper." (H)

“Before attending this classes I have been in lots of problems with paraphrasing. I didn't know where to begin and how to make sure that my paraphrasing is enough." (N)

The students' reflections showed that there was growth in understanding of textual borrowing conventions and an increase in confidence when writing and using paraphrasing to integrate sourced information in their writing. 
Volume 30, 2020

http://journals.sfu.ca/cjsdw

\section{Implementation Challenges}

The main challenge to teaching paraphrasing while considering language learners' needs is that this requires a certain depth and range of expertise (Lawrick, 2016; Thonus, 1993, 2004; Blau and Hall, 2002; Harris \& Silva, 1993) on the part of the tutor. Tutors need to provide individualized feedback and assess the students' citation knowledge, writing ability and language needs. Some students may have misconceptions about using sources, and the tutor will have to address these in a culturally sensitive way. Tutors also need to be familiar with various subject-area citation styles and will need to be able to explain grammatical structures and lexical points. Tutor training would therefore need to include a module on working with multilingual learners, content knowledge related to source use and citation, and possibly an introduction to sentence structure and grammar for academic writing.

In addition, teaching paraphrasing in this way requires several regularly scheduled sessions with the same tutor. The tutor does need to prepare for these sessions, which requires a substantial amount of time and resources that may not always be readily available (Moussu, 2013; Lawrick, 2016). Also, while the pedagogy is quite feasible in larger classes or groups as demonstrated by Wette (2015), the personalized feedback and support needed to facilitate meaningful academic literacy, individual language development and writerly growth may be compromised when teaching and giving feedback to a class or a small group.

In the present context, the university's Academic Integrity Coordinator was responsible for the referrals to the EAL specialist, and monitoring the students' progress and completion of the sessions. Although students did express that they were happy to have access to these sessions, the Academic Integrity Coordinator's involvement, and the fact that these one-to-one sessions were required to complete the Faculty of Graduate Studies post-discipline conditions, most likely facilitated attendance and completion of the modules. Despite these challenges, however, with proper training and resources, this approach to teaching paraphrasing fits the needs of the students and is feasible in the writing centre context.

\section{Conclusion}

Paraphrasing is one small component of mastering academic writing. Still, it is significant given its frequent use in academic writing and the dire consequences students face when they do not paraphrase or incorporate their sources correctly. The approach to teaching paraphrasing explained in 
Volume 30, 2020

http://journals.sfu.ca/cjsdw

this paper ensures that students have many opportunities to achieve a clear understanding of basic source use concepts and facilitates the meaningful embedding of writing from sources into their existing academic literacy schemas in a low stakes learning environment, In most situations students are expected to merely read the text and use "their own words" to produce a paraphrase, In this approach, the paraphrasing process is scaffolded and the necessary language supports are in place to help the student experience the "leap of faith" that is often necessary when moving from the phrase to the paraphrase. Furthermore, having to work through an actual paraphrase gives students a realistic awareness of the type of language, effort and time they need to invest when writing from sources, which helps them plan their time more effectively. Through this comprehensive approach to teaching paraphrasing, students learn how to read complex text carefully to comprehend it fully and to identify the information they need to support their own arguments and effectively integrate this information into their paragraphs. By emphasizing the meaningful use of sources and the utility of the paraphrase in achieving this goal, this approach moves multilingual students closer to contributing their own voices to a particular field of inquiry.

Multilingual graduate students' adjustment to western writing norms requires more than a onesize-fits-all, superficial approach to introducing them to source use and Western citation. Source integration is difficult and can be overwhelming for second language writers. Providing equal access to "one size fits all" resources is not equitable and does not promote internationalization nor inclusion. Providing academic literacy supports that take into consideration the linguistic and cultural backgrounds of graduate, multilingual students is the only way for post-secondary institutions to sustain their own pedagogical and professional integrity.

\section{References}

Aday, M. S., \& Yener, U. (2014). Understanding the buying behavior of young consumers regarding packaging attributes and labels. International Journal of Consumer Studies, 38(4), 385-393. DOI: 10.1111/ijcs.12105

Bart. M. (2016, October 4). Reader survey finds unprepared students a persistent problem. Retrieved from https://www.facultyfocus.com

Blau, S., Hall, J., \& Sparks, S. (2002). Guilt-Free Tutoring: Rethinking How We Tutor Non-Native-English-Speaking Students. The Writing Center Journal, 23(1), 23-44. 
Volume 30, 2020

http://journals.sfu.ca/cjsdw

Bradshaw, J., \& Baluja, T. (2011, September 2). Why many international students get a failing grade in academic integrity. Retrieved from https://www.theglobeandmail.com

Coffin, C., Curry, M. J., Goodman, S., Hewings, A., Lillis, T., \& Swann, J. (2005). Teaching academic writing: A toolkit for higher education. New York, NY: Routledge.

Dollahite, N. E., \& Haun, J. (2012). The grammar toolbox method. Retrieved from http://www.cengage.com

Ercegovac, Z., \& Richardson, J. (2004). Academic dishonesty, plagiarism included, in the digital age: A literature review. College \& Research Libraries, 65(4), 301-318. DOI: 10.5860/crl. 65.4.301

Frazier, L., Carlson, K., \& Clifton, C. (2006). Prosodic phrasing is central to language comprehension. Trends in Cognitive Sciences, 10(6), 244-249. DOI: 10.1016/j.tics.2006.04.002

Graff, G., \& Birkenstein, C. (2014). They say/I say. The moves that matter in academic writing, (3rd ed.). New York, NY: W.W. Norton \& Company.

Hall, J. (2005). Plagiarism across the curriculum: How academic communities can meet the challenge of the undocumented writer. Across the Disciplines, 2005(2). Retrieved from http://wac.colostate.edu/atd

Harris, M., \& Silva, T. (1993). Tutoring ESL students: Issues and options. College Composition and Communication, 44(4), 525-537.

Hirvela, A. \& Du, Q. (2013) "Why am I paraphrasing?": Undergraduate ESL writers' engagement with source-based academic writing and reading. Journal of English for Academic Purposes, 12, 87-98. DOI: 10.1016/j.jeap.2012.11.005

Jiang, X. (2016). The role of oral reading fluency in ESL reading comprehension among learners of different first language backgrounds. The Reading Matrix, 16(2), 227-242. Retrieved from http://www.readingmatrix.com

Lawrick, E. (2016, Fall). Supporting multilingual students in college. College ESL Quarterly. Retrieved from http://www.languageartspress.com

Moniz R., Fine, J., \& Bliss, K. (2008). The Effectiveness of Direct Instruction and Student-Centered Teaching Methods on Students' Functional Understanding of Plagiarism. College \& Undergraduate Libraries, 15 (3), 255-279. DOI: 10.1080/10691310802258174

Moussu, L. (2013). Let's talk! ESL students' needs and writing center philosophy. TESL Canada Journal, 30(2), 55-68. DOI: 10.18806/tesl.v30i2.1142

Norton, B. (2000). Identity and language learning: Gender, ethnicity and educational change. Harlow, UK: Longman/Pearson Education Limited 
Volume 30, 2020

http://journals.sfu.ca/cjsdw

Norton, B. (1997). Language, identity, and the ownership of English. [Introduction, Special Issue] TESOL Quarterly, 31(3), 409-429.

Norton Peirce, B. (1995). Social identity, investment, and language learning. TESOL Quarterly, 29(1), 9-31.

Pennycook, A. (1996). Borrowing others' words: Text, ownership, memory, and plagiarism. TESOL Quarterly, 30. 201-230. DOI: 10.2307/3588141

Powers, J. (1993). Rethinking writing center conferencing strategies for the ESL writer. The Writing Center Journal, 13(2), 39-47.

Rafoth, B. A. (2015). Multilingual writers and writing centers. Logan, UT: Utah State University Press.

Rasinski, T., Yildirim, K., \& Nageldinger, J. (2011). Building fluency through the phrased text lesson. The Reading Teacher, 65(4), 252-255. DOI: 10.1002/TRTR.01036

Soto, J., Sulekha, A., \& McGee, E. (2004). Plagiarism avoidance: An empirical study examining teaching strategies. Journal of College Science Teaching 33(7), 42-48.

Thomas, P. (Aug 11, 2018). Low-stakes environments and embracing the value of failing. Retrieved from https://medium.com

Thonus, T. (1993). Tutors as teachers: Assisting ESL/EFL students in the writing center. The Writing Center Journal, 13(2), 13-26.

Thonus, T. (2014). Tutoring multilingual students: Shattering the myths. Journal of College Reading and Learning, 44(2), 200-213. DOI: 10. 1080/10790195.2014.906233

Wette, R. (2014). Teachers' practices in EAP writing instruction: Use of models and modeling. System, 42(1), 60-69. DOI: 10.1016/j.system.2013.11.002

Wette, R. (2015). Teacher-led collaborative modelling in academic L2 writing courses. ELT Journal, 69(1), 71-80. DOI: 10.1093/elt/ccu043

Wong Fillmore, L., \& Fillmore, C.J. (2012) What does text complexity mean for English learners and language minority students? Retrieved from https://ell.stanford.edu

Wong Fillmore (n.d.). Juicy sentence guidance. Retrieved from https://achievethecore. org 